\title{
تقييم جودة بعض عصائر البرتقال بالسوق الليبي
}

\author{
عبد الباسط علي خليفة'، جمعة السيد الطاهر²، علي محمد أبوصلوعة3، علي ضو عبعوب4 \\ 4،2،1 قسم هندسة بيئية، كلية الهندسة - صبراتة، جامعة صبراتة \\ 3قسم هندسة كيميائية، كلية الهندسة - صبراتة، جامعة صبراتة
}

الملخص

تضمن البحث دراسة لتقييم جودة بعض عصائر البرتقال المحلية والمستوردة في السوق الليبي

وذلك بمطابقتها للمواصفات القياسية الليبية رقم 37 لسنة 2009م من ناحية تركيز بعض العناصر الكيميائية ونسبة الحموضـة الكلية مقدرة بحمض الستريك اللامـائي كذلك التحاليل الجرثومية و قياس نسبة المواد الصلبة الذائبة و الأس الهيدروجيني (PH). حيث تم إجراء التحاليل وأخذت العينات من داخل السوق الليبي لعدد 8 شركات مصنعة للعصائر منها 5 شركات محلية و3 شركات غير محلية. تبين من خلال النتائج الكيميائية المتحصل عليها أن نسبة الحموضـة الكلية المقدرة بحمض الستريك اللامائي في جميع العينات مطابقة للمواصفات القياسية الليبية. أما بالنسبة لنسبة المواد الصلبة الذائبة فكانـت العينـة رقم 8 تقدر نسبة المـواد الذائبة فيها 6.4\% التي تعد أقل مـن المعدل المطلوب للمواصفات الليبية التي يجب ألا تقل عن 12\% بالوزن أمسا بالنسبة لقياس الأس الهيدروجيني فكانت جميع العينات ضمن الحد المسموح به باستثناء العينـة رقم 8 فكانت 2.71 وهي أقل من الحد المسموح به للمواصفة التي تتراوح بين 3-4. أما بالنسبة لتحاليل العناصر الثقيلة وهي (الرصاص الزرنيخ- كادميوم - الخارصين - النحاس) كانت جميع العينات ضمن الحد المسموح بـه باستثناء العينة رقم 8 فقد تجاوزت الحدود المسموح بها لعناصر الكادميوم والزرنيخ و الرصـاص ، أما بالنسبة للتحاليل الميكروبية فتبين من خلال النتائج أن جميع العينات كانت خالية من Yeast bacteria غير مطابقة للمواصفة القياسية الليبية رقم 37 . 
المقدمة

شهدت صناعة العصائر والمشروبات تطورا ملحوظا في العقود الأخيرة سواء من حيث كمية الإنتاج أو التقنيات المستعملة إضافة لتحضير أنواع مبتكرة من العصائر والمشروبات التي تحتوي على العديد من العناصر الغذائية مثل الفيتامينات والأملاح المعدنية فضلا عن السكريات والألياف المفيدة للهضم إلا أن العصائر و المشروبات تعد فقيرة من الدهون والبروتينات

\section{تعريف العصير}

هو سائل طبيعي غير متخمر لكنـه قابل للتخمر لنوع واحد أو أكثر من ثـار الفاكهة أو الخضر السليمة الناضجة والمحتوية على اللب كله أو جزء منه والخالي من البذور والقشور والألياف الخشنة والمعاملة بإحدى طرق الحفظ المناسبة إذا لم يكن معدا للاستهلاك مباشـرة بعد تحضيره شريطة احتفاظه بصفاته الطبيعية والكيميائية والغذائية لنوع واحد أو أكثر من ثمار الفاكهة أو الخضر في هذه الحالة يجب ان تذكر عبارة عصير فواكه محضر من عصير مركز وتستبدل كلمة فواكه بأسماء الفاكهة أو الفواكه المركزة التي صنع منها العصير • (يوسف 2008 )

أنواع العصائر

1. النكتار : يقصد بالنكتار الفاكهة أو بأنه عصير لب الفاكهة، المضـاف لـه قدر مناسب من الهحلول السكري وحمض عضوي مناسب مثل حمض الليمون Citric acid أو حمض التفاح Malic acid ، وقد يضاف له حمض الأسكوبيك كمانع أكسدة ، ويحفظ بحيث يصبح الناتج ·

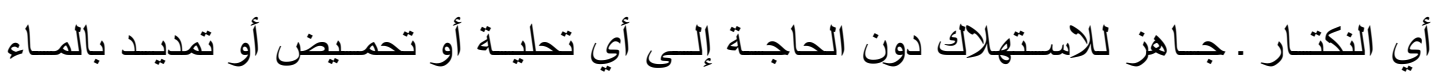

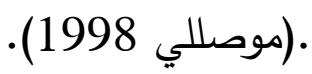

2. الثراب (مشروب): ويقصد به عصير الفاكهة المصفى من القشور والبذور والألياف الخشنة غير المتخمر والمضاف له حمض عضوي بكمية مناسبة وكمية من السكر حتى يصل تركيز السكر فيه بين40 ـ 60\% والمحفوظ بأحد طرق الحفظ المناسبة كالبسترة أو التجميد أو إضافة المواد الحافظة الكيميائية. وطبيعي عند استهلاكه يجب تمديده بقدر مناسب من الماء لتصل درجة تركيز السكر فيه الى المستوى المطلوب من الحلاوة المقبولة التي يرغبها المستهلك وهي 
بين 10 ـ 13 \%. ويصنع الشراب من العديد من عصائر الفاكهة ، ويأتي في مقدمتها البرتقال

$$
\text { والليمون والتوت الثامي و الفريز والرمان. (حسين 2000م). }
$$

\section{مشكلة الدراسة}

نظـرا لتزايـــ أنـواع العصـائر المستوردة والمحليـة الصـنع في السـوق الليبـي وإقبـال المـواطنين على

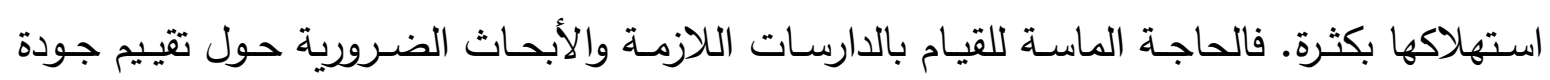
العصائر المتوفرة في السوق الليبي وكيفية مراقبتها. وخلوها من التلوث بكل أنواعه ومدى مطابقته للموصفات القياسية الليبية واقتراح عدة توصيات لغرض جعل السوق الليبي خالي من المنتجات الغذائية الضارة والملوثة، ويمكن حصر أهمية الدراسة في المحاور التالية:

1. - التعرف على أنواع البكتيريا الموجودة في العينة.

2 . تحديد مدى خطورة العناصر الثقيلة على صحة الإنسان. 3. تحديد ملائمة العصائر من عدمه.

ولكي تستكمل الدراسة كل جوانب التقييم يمكن طرح الأسئلة التالية: 1. ما نسبة تركيز بعض العناصر الكيميائية بمشروب البرتقال المحلي والمستورد؟ 2. هل نسبة العناصر الكيميائية ضمن الحدود المسموح بها في مشروب البرتقال؟ 3. ما مدي صـلاحية استهلاك عصير البرتقال بعينة الدراسة عند مقارنتها بالمواصفات القياسية

$$
\text { وتهاف الدراسة إلى: }
$$

1. دراسة أنواع من عصائر البرتقال (شراب) من المنتجات المحلية والمستوردة السوق الليبي في الفترة من يناير إلى مايو للعام 2017م في منطقة غرب ليبيا من طرابلس إلى رأس جدير . 2. تقييم جودة العصائر المستوردة والمحلية بالسوق الليبي. 3. مدى مطابتها للموصفات القياسية الليبية. 
4. تقدير تركيز بعض العناصر الثقيلة في عصير البرتقال.

الارسات السابقة

دراسة حارث يعرب محمود ، جامعة البصرة ـ أجريت هذه الدراسة بمنطقة البصر بالعراق حول تقدير بعض العناصر المعدنية الثقيلة في عينات مختلفة من عصير الفواكه المعلبة.

ركزت هذه الدراسة على تقدير مستويات بعض العناصر المعدنية (الثقيلة) في خمسة أصناف من عصير الفواكه المعلبة باستخدام مطياف الامتصـاص الذري (ASS). تراكيز أنواع المعادن الثقيلة المدروسـة تراوحت بين 2.45) Pmm 1 1.50) Pmm ، 15.01) للحديد

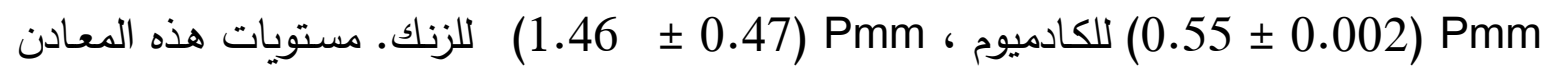
الثقيلة تجاوزت الحدود الأمنية عدا الزنك.

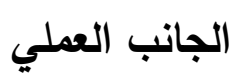

جمع العينات

جمعت عينات عصير البرتقال المعلبة من متاجر في منطقة الدراسة بعد فترة تخزين تراوحت بين (1) - 10) أشهر من تاريخ الإنتاج وبمعدل 3 عينات لكل منها وهي موضحة بالجدول (1). الجدول (1): يوضح عينات عصير البرتقال.

\begin{tabular}{|c|c|c|c|c|}
\hline الشركة المصنعة & الدولـــــة & عدد العينات & اســـم العصـــير & ت \\
\hline جهينة للعصائر & 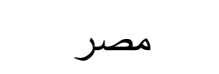 & 3 & عصير جهينة التر & .1 \\
\hline راوخ للعصائر & ليبيا & 3 & عصير راوخ التر & .2 \\
\hline زين للعصائر & ليبيا & 3 & عصير زين التر & .3 \\
\hline الريحان للعصائر & ليبيا & 3 & عصير الريحان التر & .4 \\
\hline سعيد للعصائر & ليبيا & 3 & عصير سعيد التز & .5 \\
\hline المروج للعصائر & ليبيا & 3 & عصير المروج 200 ملي & .6 \\
\hline Don Simon & المانيا & 3 & 335 Don Simon & .7 \\
\hline Dellos & كوريا الجنوبية & 3 & 335 Dellos & .8 \\
\hline
\end{tabular}


تم إجراء العديد من التحاليل المخبريـة للتأكد من استفاء هذه العصائر للشروط والمواصفات القياسية المعمول بها ومن أهم هذه التحاليل ما يلي:

التحليل الكيميائي

تقدير نسبة الحموضة الكلية مقدرة كحمض الستريك اللامائي بطريقة المعايرة

حض الستريك اللامائي هو مركب أبيض اللون صيغته الكيميائية 192.13 وزنه الجزيئي كثافته 1.665 جرام / سم ودرجة انصهاره 135 مُ وهو قابل للذوبان في الماء وشحيح الذوبان في لكئي المذيبات العضوية.

يستخدم حمض الستريك كمادة محضة ولمعالجة اللون في بعض الأغذية، ولتحسين النكهة ، وكعامل

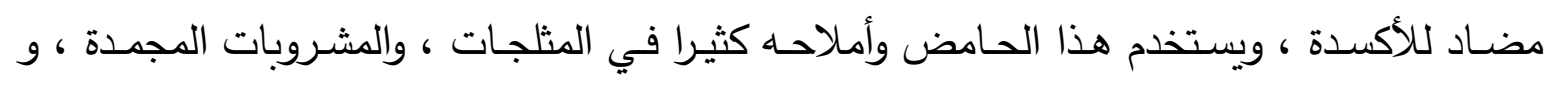
السلطات ولحفظ الفاكهة وفي المربى.

يعتبر حمض الستريك من المواد الحامضية المهمة في صناعة المشروبات الغازية حيث يضفى عليها نكهة الليمون المحببة ، وكذلك يضاف إلى المشروبات غير الغازية ذات نكهة غير طبيعية "نكهة صناعية " .

يستخدم حمض الستريك تجاريـا وعلى نطاق واسع كمادة مضـادة للأكسدة وتقلل من تفاعلات اللون البني. (جعفر 2000م )

المواد المستخدمة وطريقة العمل

"لميدروكسيد الصوديوم NaOH "

دليل Phenolphthalein

طريقة العمل

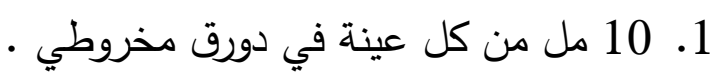

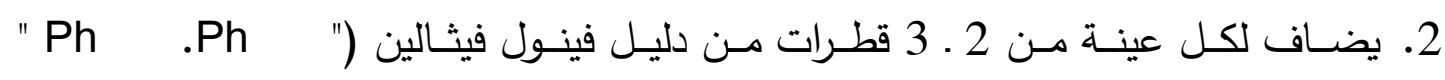
) وهذا الدليل عديم اللون في الوسط الحامضي ثم يوضع الحجم 
المعلوم من العينـة في دورق مخروطي ذي سـعة مناسبة وباستعمال محلول هيدروكسيد الصوديوم المعلوم العيارية 0.1 يتم التنقيط المباشر عليها بالسحاحة

3. نقطة التعادل هي تحول اللون إلى اللون الوردي الخفيف ومنها تحسب عدد مليمترات

هيدروكسيد الصوديوم التي ألزمت لمعادلة الحمض في عينة العصير •

يعبر عن حمض الستريك اللامائي بالنسبة المئوية كما سيتضح في المعادلة الآتية :.

نسبة الحموضة الكلية مقدرة كحض الستريك اللامائي = معامل حمض الستريك × حجم هيدروكسيد الصوديوم •

\section{قياس الرقم الهيدروجيني PH}

يعد ضبط المنتج الغذائي من العوامل المهمة في عملية الحفظ حيث إن أملاح المواد الحافظة المستخدمة تكون أكثر فاعلية في تثبيط نشاط الميكروبات عند تعمل المواد الحمضية كمواد حافظة أيضا نظرا لقدرتها على خفض PH المنتج الغذائي مما يثبط من نشاط الميكروبات وبالتالي يقل من كل من الوقت اللازم للتعقيم على مكونات المنتج فيتم الحصول على منتج ذي جودة أفضل .( جعفر 2000م ).

الجهاز المستخدم

جهاز الـ PH. meter

مقياس الأس الهيدروجيني هي أداة الكترونية تستعمل لقياس الأس الهيدروجيني (درجة الحموضـة أو القاعدية) لسائل معين • عادة ما يتكون من قطب خاص (قطب زجاجي) متصل بمقياس إلكتروني

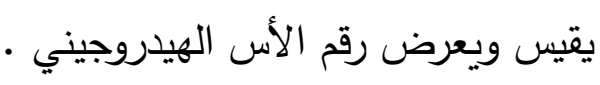




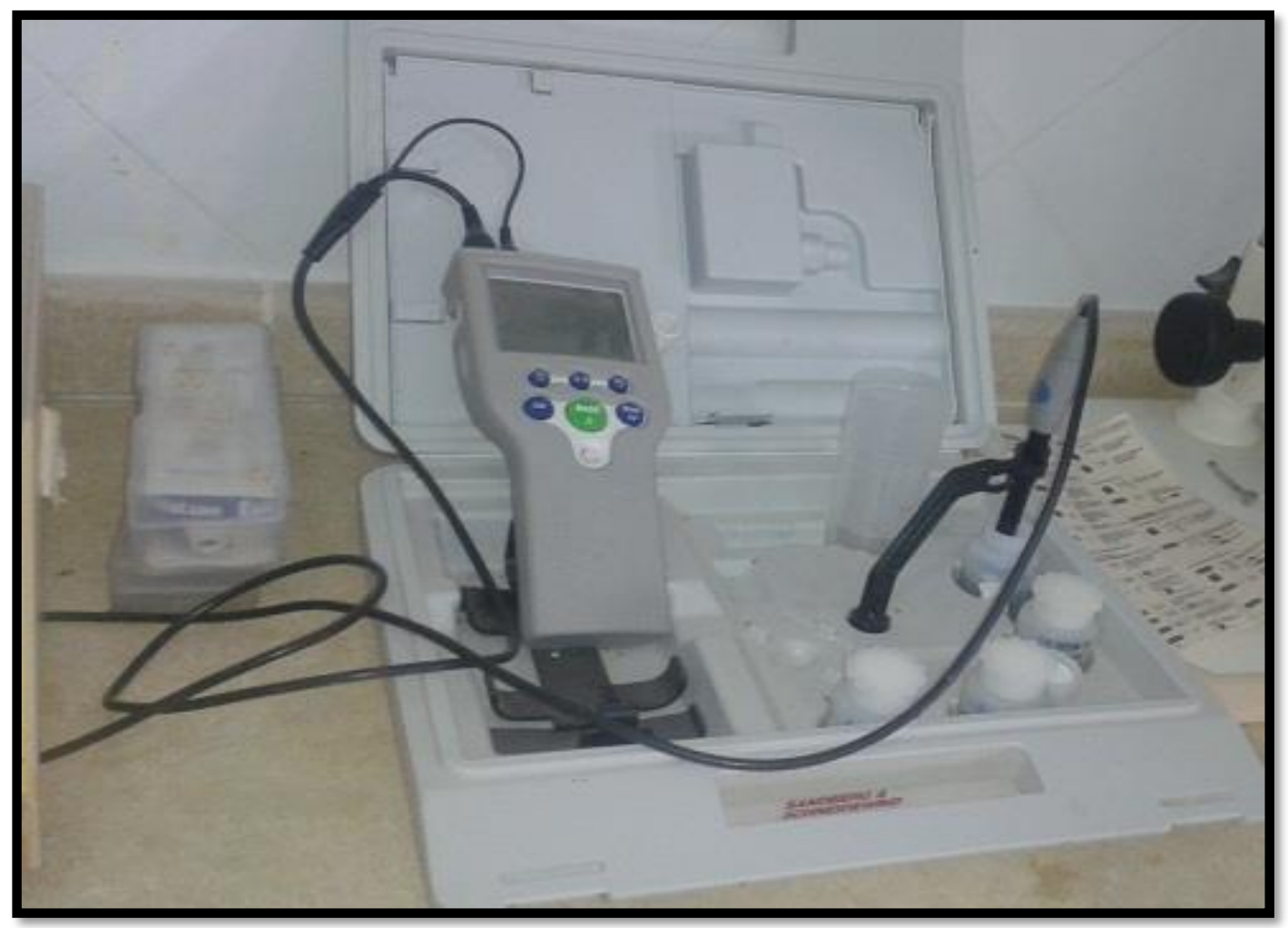

(الثكل (1): ( جهاز PH meter).

قياس المواد الصلبة الذائبة الكلية TSS

تقاس المواد الصلبة الذائبة الكلية في العصير باستخدام جهاز Refractometer وهذا الجهاز يعطي قياسا للمواد التي تكسر الثعاع الضوئي ، وتثمل السكريات المختلفة مع بعض الأملاح العضوية ،

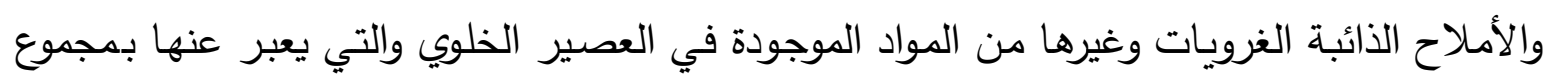
المواد الصلبة الذائبة (TSS) (Total soluble solids) (

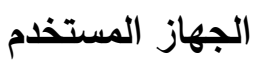

\section{Brix Refractometer}

يمتاز الجهاز بإمكانية توصيله بحمام مائي حتى تتم القراءة في درجة حرارة 20 مُ ، ولاستخدام هذا الجهاز لا بد من وجود عصير رائق تماما يضاف منه على العسة حتى يتم تغطيتها بالكامل ونقرأ مباشرة كنسبة مئوية من الجهاز TSS 


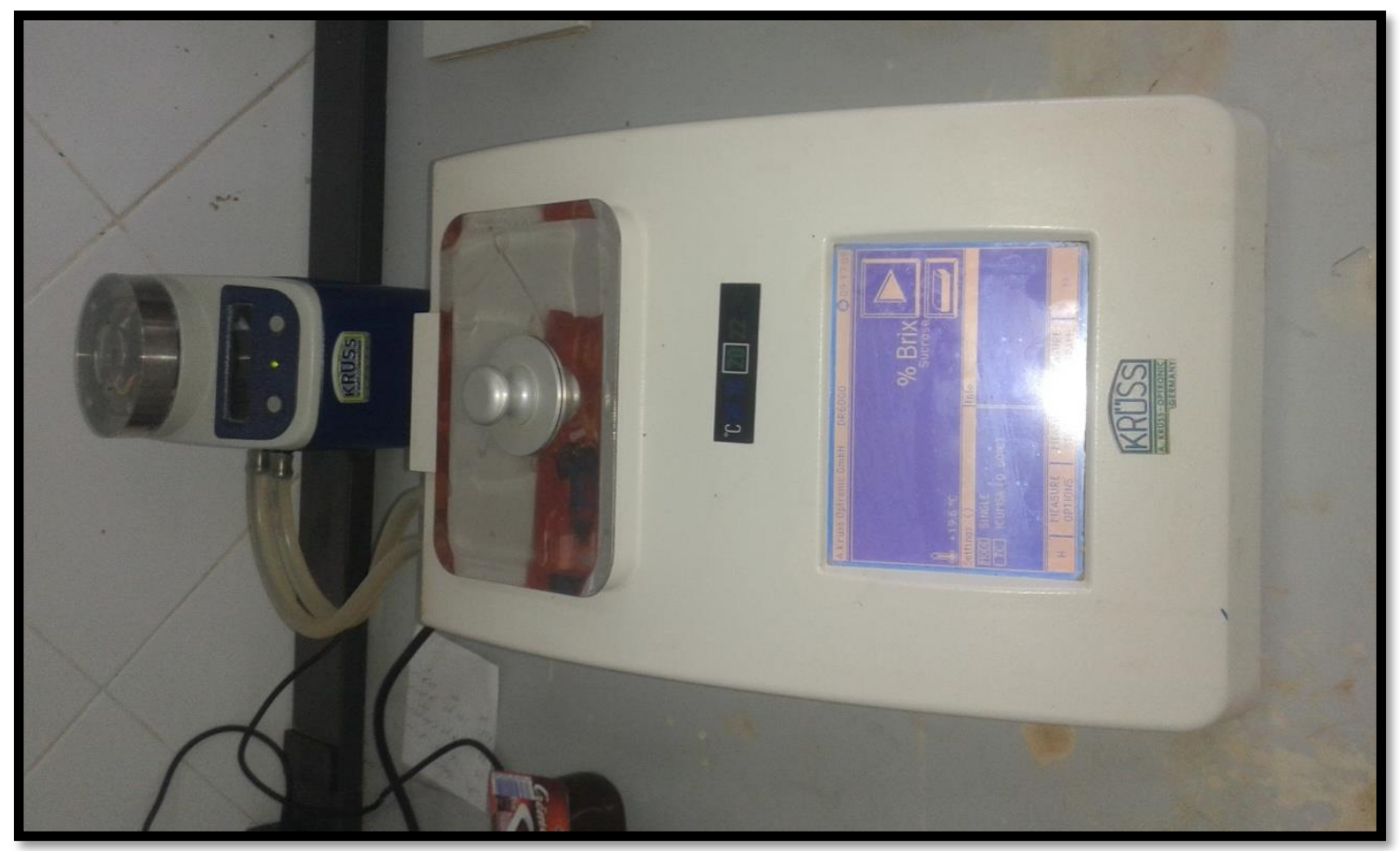

الثكل (2): (جهاز Brix) لقياس TSS.

تحليل العناصر الثقيلة

المعـادن الثقيلـة هي تلك العناصـر التي كثافتها خمس مـرات ضـفف كثافة المـاء، تسبب أيونـات العناصر الثقيلة ومركباتها مدى واسع من السمية للكائنات الحية حيث يتراوح هذا المدى من السمية المميتة والسمية الثانوية وذلك اعتمادا على فترة تعرض الكائن الحي للمادة السامة ، وتقاس السمية المميتة في المياه بقيهة 50| وهذه القيمة هي الجرعة القاتلة ، الجرعة غير القاتلاة في هذا الكائن يمكنها أن تئثر على حياته.

والكائنات الحية تحتاج إلى كميات ضئيلة من بعض العناصر المعدنية الثقيلة وعندما تتجاوز كمياتها حدا معينا يظهر لها أضرار صحية فتعد حينئذ ملوثات.

الأدوات المستخدمة:

1. أنابيب اختبار

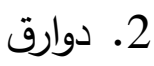

3. أقماع 


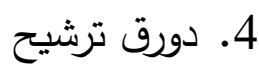

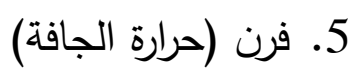

6. صفيحة تسخين

اسم الجهاز المستخدم

مطياف الامتصاص الذري AAS (280FZ) Atomic Absorption spectrometer. طريقة عمل الجهاز

يعمل مطياف الامتصـاص الذري Atomic Absorption spectrometer على فحص أطوال موجات الفوتونات الممنصة أثناء إثارة ذرات العناصر ، ومن المعروف أن كل عنصر يبعث مجموعة مميزة من الأطوال الموجية المنفصلة طبقا لتركيبه الإككتروني ، وبدراسة هذه الأطوال الموجية يمكن معرفة العناصر المكونة للعينة.

تقوم مطيافات الامتصاص والانبعاث الذري بتقدير العناصر في محاليلها كطريقة من طرق القياسات

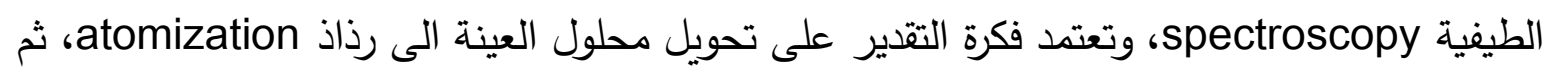
خلط الرذاذ مع مخلوط من الغازات مثل الأسيتيلين والهواء أو الأسيتلين ، وأكسيد النيتروز ويتم حرق العنصر بواسطة اللهب الناتج عن خلط هذه الغازات ويتحول العنصر الى الصورة الذرية والتي تتعرض الى لمبة كاثود Hollow cathode lamp خاصة بالعنصر المراد قياسه. التحاليل الميكروبية

تشمل هذه التحاليل كل من :

E.coli .1

Yeast bacteria .2

3.العدد الكلي للبكتيريا 
(Escherichia coli ) ايثيريشيا كولا

هي عبارة عن بكتيريـا سالبة صبغة جرام غير مكونـة للابواغ وهي متحركة لاحتوائها على أسوا ط متعددة وتمتلك حافظة أو حافظة دقيقة تكسبها اللزوجـة عند نمو المستعمرات البكتيريـة في الوسط فيط الغذائي المناسب كما أنها غير هوائية اختيارية لها القدرة على إنتاج غاز • ( التومي 2008 ) ـ ل

بكتيريا الخمائر (Yeast bacteria)

عبارة عن فطريـات وحيدة الخليـة لا تكون هيفات ، بيضـاوية الثكل أو كرويـة تحتوي على نواة.

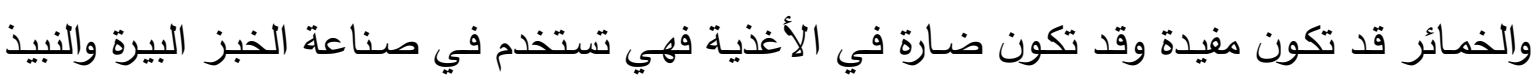

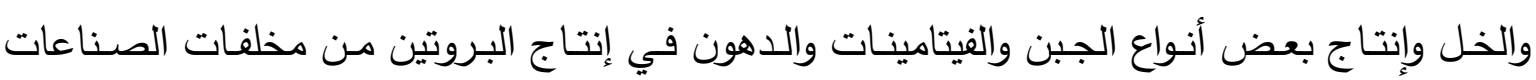
والغذائية ومنتجات النفط وتكون الخمائر ضـارة عندما تتمو تسبب فسـادا لعصـائر الفاكهة والعسل والمربيات والجبن و المخلات والمشروبات الكحولية واللحوم والألبان و المنتجات (الأحياء الدقيقة في الأغذية 1429 هـ ) م ن.

العدد الكلي للبكتيريا (Total count) الأدوات والأجهزة المستخدمة

1- كابينة واقية ( حجر السلامة )

2- 2 - 2 - 2 - 2باق بتري معقدة

3- ماصات حجم 1ml معقة

4- محلول التخفيف

5- لهب

6- - الحاضنة

المواد المستخدمة

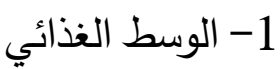


E.coli Macconkey sorbitol Ager base -1

Yeast bacteria تم الكثف عن Potato Dextrose Ager -2

Total count تم الكثف عن العدد الكلي للبكتيريا Plant count Ager -3

. Buffer Peptone water -4 محلول التخفيف

طريقة العمل

يتم تخفيف العينة وذلك بأخذ $1 \mathrm{ml}$ من عينة العصير ويضاف إليها يؤخذ 1ml من العينة المخفقة ويضاف إليها 9mlمن محلول التخفيف تترك لمدة 3-4 ساعات داخل الكابينة الواقية (حجر السلامة ) يتم زرع العينات المخففة داخل الوسط الغذائي و توضـع الأوساط التي تم زرع العينات فيها في الحاضنة بدرجة حرارة 30-37 مُ0لمدة تتراوح بين 24-48 ساعة . النتائج والمناقشة التحاليل الكيميائية

الجدول (2): يوضح تحليل الكيميائية Citric acid و و

\begin{tabular}{|c|c|c|c|}
\hline \multicolumn{3}{|c|}{ نوع } & \multicolumn{1}{c}{} \\
\hline TSS & PH & Citric acid & 1 \\
\hline$\% 14.7$ & 3.49 & $\% 0.34$ & 2 \\
\hline$\% 14.6$ & 3.22 & $\% 0.50$ & 3 \\
\hline$\% 12.6$ & 3.00 & $\% 0.20$ & 4 \\
\hline$\% 12.8$ & 3.00 & $\% 0.42$ & 5 \\
\hline$\% 13.9$ & 3.44 & $\% 0.39$ & 6 \\
\hline$\% 12.2$ & 3.47 & $\% 0.75$ & 7 \\
\hline$\% 12.3$ & 3.43 & $\% 0.51$ & 8 \\
\hline$\% 6.4$ & 2.71 & $\% 0.31$ & \\
\hline & & & \\
\hline
\end{tabular}


نتائج التحليل الكيميائي

حض السيتريك اللامائي Citric acid

جميع العينات ضمن الحدود المسموح بها للمواصفات القياسية الليبية لسنة 2009م التي تتص على: ألا تزيد نسبة الحموضة الكلية على 1\% بالوزن مقدرة كحض ستريك لا مائي.

الأس الهيدروجين PH

جميع العينات مطابقة للمواصفات القياسية الليبية باستثناء العينة رقم 8 حيت كان تركيز وهي أقل من المعدل المطلوب ضمن المواصفات القياسية الليبية لسنة 2009م والتي يجب أن يتراوح تركيز الأس الهيدروجين لعصير البرتقال بين (3-4)

المواد الصلبة الذائبة (TSS ( Total soluble solids)

جميع العينات مطابقة للموصفات القياسية الليبية باستثناء العينة رقم 8 لم تطابق المواصفات التي تتص على :

ألا تقل نسبة المواد الصلبة الذائبة الكليـة عن 12\% بـالوزن مقدرة بواسطة جهاز قيـاس معامـل الانكسار الضوئي (الرفراكتوميتر ) عند درجة حرارة 20 م. (المواصفات لقياسية الليبية 2009).

تحليل العناصر الثقيلة

الجدول (3): يوضح التحاليل الكيميائية لبعض العناصر الثقيلة.

\begin{tabular}{|c|c|c|c|c|c|}
\hline \multicolumn{5}{|c|}{ نوع العنصر } & \multirow[b]{2}{*}{ رقم العينة } \\
\hline نحاس & خارصين & كادميوم & رصاص & الزرنيخ & \\
\hline 0.03 & 0.72 & 0.005 & 0.006 & 0.001 & 1 \\
\hline 0.03 & 0.74 & 0.005 & 0.006 & 0.001 & 2 \\
\hline 0.03 & 1.07 & 0.005 & 0.006 & 0.001 & 3 \\
\hline 0.03 & 0.44 & 0.005 & 0.006 & 0.001 & 4 \\
\hline 0.03 & 0.48 & 0.005 & 0.006 & 0.001 & 5 \\
\hline
\end{tabular}




\begin{tabular}{|c|c|c|c|c|c|}
\hline 0.03 & 0.31 & 0.005 & 0.006 & 0.001 & 6 \\
\hline 3.2 & 3.1 & 0.004 & 0.003 & 0.001 & 7 \\
\hline 2.12 & 2.22 & 2.5 & 1.5 & 1.0 & 8 \\
\hline
\end{tabular}

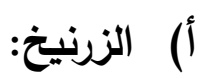

يتضـح من نتائج الجدول (3) ان قيم تركيز عنصر الزرنيخ للعينات المدروسة في السوق الليبي تتراوح بين (mg/kg 1.001) ، واتضح من خلال مقارنة هذه النتائج مع المواصفات الليبية التي تقدر ب(mg/kg 1) وبهذا يتضح بأن جميع العينات ضمن الحدود المسموح بها وصالحة ل للاستهلاك.

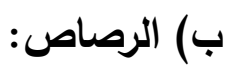

أوضحت نتائج تركيز عنصر الرصاص المبينة في الجدول (3) لعينات عصير البرتقال في السوق الليبي هي ضمن الحدود المسموح بها باستثناء العينة (8) التي كان تركيز عنصر الرصاص فيها يقدر بـ(mg/kg1.5) وهي أعلى بكثير من الحد المسموح به ضمن المواصفات القياسية الليبية

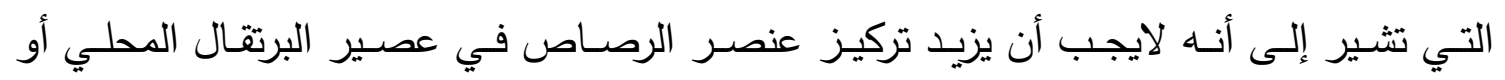
المستورد عن (mg/kg0.05) (

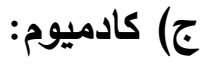

تراوح تركيز الكـادميوم في العينـات مـابين (0.004- mg/kg0.005) وطبقـا للمعايير الليبيـة القياسية لعصير البرتقال فإن الحد المسموح بـه هو (mg/kg0.05) عليه فإن جميع العينات صالحة للاستهلاك ماعد العينة رقم (8) كان تركيز عنصر الكادميوم فيها هو 2.5 mg/kg وهي نسبة عالية بمقارنتها بالموصفات الليبية وبتالي هي ليس ضمن الحدود المسموح بها وغير صالحة

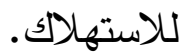




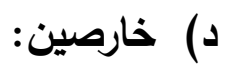

طبقا للمعايير القياسية لعصير البرتقال في السوق الليبي فإن الحد الأقصى المسموح به لتركيز الخارصين هو mg/kg5 ، عليـه فـإن جميع العينـات كانت ضـمن الحدود المسموح بها طبقـا

للمواصفات الليبية .

ه) (النحاس:

تراوحت نتائج قياس تركيز عنصر النحاس لعينات الدراسة ما بين (0.03- 3.2) وعند الاطلاع على النسب المسموح بها ضمن المواصفات الليبية لنكثار البرتقال - مشروب البرتقال نجد أن الحد الاقصى للنحاس هو 5 mg/kg ، وعند مقارنتها بالمواصفات الليبية نجد ان جميع العينات ضمن الحدود المسموح بها .

التحليل الجرثومية

الجدول (4): نتائج التحاليل ho[ve,Idm.

\begin{tabular}{|c|c|c|c|}
\hline Total count & Yeast bacteria & E.coli & رقم العين| \\
\hline+ & + & + & 1 \\
\hline+ & + & + & 2 \\
\hline- & + & + & 3 \\
\hline+ & + & + & 4 \\
\hline+ & + & + & 5 \\
\hline+ & + & + & 6 \\
\hline+ & + & + & 7 \\
\hline+ & + & + & 8 \\
\hline
\end{tabular}


نتائج التحليل الجرثومي

:E.coli •

عند إجراء التحليل الجرثومي لبكتيريـا E.coli وجدت جميع العينات خالية مـن التلوث و مطابقـة للمواصفات القياسية الليبية لسنة 2009 ـ :Yeast bacteria •

وعند اجراء التحاليل للخمائر ظهرت النتائج جميعها خالية من التلوث ومطابقة للمواصفات القياسية الليبية لسنة 2009.

\section{:Total count •}

جميـع العينـات مطابقـة للمواصـفات القياسية الليبيـة باستثناء العينـة رقم 3 لوحظ وجود تلوث جرثومي بها وتعد غير مطابقة للمواصفات القياسية الليبية التي تنص على أن تكون خالية من الأحياء الدقيقة المسببة للمرض أو الفساد أو سمومها.

المراجع

عبدالله محمد جعفر 2000"المواد الحافظـة والمضـافة في الصناعات الغذائية " الدار العربية للنشر والتوزيع الطبعة الاولي.

عبدالرزاق سليمان التومي (2008م)، ومحمد الطـاهر علي سعد، بكتيريولوجيـا مياه الثرب، مركز بحوث التتنيات الحيوية.

م.بشير حسين يوسف (1429هـ) ، العصلئر والمشروبات ، مطابع مدينة الملك عبدالعزيز للعلوم والثقنية.

موصللي، حسين (200م)، تصنيع وحفظ عصائر الفاكهة ومركزاتها منشورات دار علاء الدين للنشر والتوزيع والترجمة. 